\title{
Flexural buckling behaviour of high strength steel columns under fire conditions
}

\author{
Dorothy A. Winful *,abc, Sheida Afshan ${ }^{\mathrm{a}}$, Katherine A. Cashell ${ }^{\mathrm{a}}$, Adrienne M. Barnes ${ }^{\mathrm{b}}$, Richard J. \\ Pargeter $^{\mathrm{b}}$ \\ ${ }^{a}$ Brunel University London, Dept. Civil Engineering, Uxbridge \\ dorothy.winful@brunel.ac.uk, sheida.afshan@brunel.ac.uk,katherine.cashell@brunel.ac.uk \\ ${ }^{\mathrm{b}}$ TWI Ltd, Great Abington, Cambridge \\ dorothy.winful@affiliate.twi.co.uk, adrienne.barnes@twi.co.uk,richard.pargeter@twi.co.uk \\ ${ }^{\mathrm{c}}$ National Strucutral Integrity Research Centre (NSIRC), Great Abginton, Cambridge
}

\begin{abstract}
In this paper, a numerical modelling study using the finite element (FE) analysis package ABAQUS [1] has been carried out to study the flexural behaviour of square and rectangular hollow section columns made from high strength steel (HSS) grades S690QL and S700MC at temperatures up to $800^{\circ} \mathrm{C}$. The FE model was validated using existing experimental data and then parametric studies were performed on columns with varying length and cross-sectional properties. The results have been compared with recommendations given in Eurocode 3 Part 1-2 [2]. The analyses showed that the Eurocode is generally conservative with respect to the buckling coefficients derived and safely predicts the buckling behaviour resistance of columns made from S700MC and suggest a lower buckling curve may be needed for S690QL. It was also shown that the $0.2 \%$ proof stress rather than the stress at $2 \%$ total strain is a better parameter for deriving buckling curves in fire.
\end{abstract}

Keywords: high strength steel, fire, buckling response, EN 1993-1-2

\section{INTRODUCTION}

High strength steels (HSS) defined herein as material with a yield strength between 460 and $700 \mathrm{~N} / \mathrm{mm}^{2}$ in accordance with Eurocode 3 [3] are increasingly being utilised in structural applications, in particular for long span structures where there are environmental and economic benefits of using this material over normal strength steel. Structures should meet the legal requirements for fire resistance (i.e. the ability of a structure to maintain its function for a prescribed amount of time in a fire [4]) and this involves having an understanding of how structural elements perform in an event of a fire. To date, there are limited performance data and design guidance rules for the flexural buckling behaviour of HSS under fire conditions. The current structural fire design guidelines given in Eurocode 3 Part 1-2 [2] were derived based on data from tests on steel columns made from steels with yield strengths less than $460 \mathrm{~N} / \mathrm{mm}^{2}$. There is a considerable amount of work in the literature on the buckling behaviour of conventional steel grades (e.g S355) at elevated temperatures (e.g. [5-7]). Most of this work includes experiments and numerical modelling but, for HSS grades, there are very limited studies [8].

In this paper, a numerical modelling study was carried out to investigate the structural performance and design of high strength steel columns in fire. The nonlinear finite element analysis package ABAQUS [1] was used to develop and validate numerical models for predicting the elevated temperature resistance of high strength steel columns. A parametric study was then conducted, which incorporated the elevated temperature stress-strain relationships of S690QL and S700MC from a parallel experimental programme [9]. Results from that experimental study, showed that S700MC had better strength retention properties than $\mathrm{S} 690 \mathrm{QL}$ at temperatures up to $800^{\circ} \mathrm{C}$, and this is likely related to the alloying content and production route of these steels. S700MC is thermomechanically control processed (M) and suitable for cold forming (C), whilst S690QL is quench and tempered (Q) 
and meets the minimum impact energy of $30 \mathrm{~J}$ at $-40{ }^{\circ} \mathrm{C}(\mathrm{L})$. The aim of this study is to generate data on the structural performance of Class 1 and Class 3 columns made from these steel grades at temperatures up to $800^{\circ} \mathrm{C}$ and assess the suitability of the Eurocode buckling curves [2] for HSS columns.

\section{DEVELOPMENT AND VALIDATION OF THE NUMERICAL MODEL}

\subsection{Overview}

In the absence of elevated temperature tests on HSS columns in the literature, the finite element (FE) models were validated against (i) the ambient temperature experiments on high strength steel columns reported by Wang and Gardner [10] and (ii) the elevated temperature tests on columns made from mild strength steel reported by Pauli et al. [7]. Wang and Gardner [10] conducted a series of tests on S460N and S690Q hot-finished HSS square hollow section (SHS) columns which were pinned at both ends and allowed in-plane rotation of the member about one axis only. Both test programmes included measurements of the material properties and geometric dimensions as well as the local and global geometric imperfection amplitudes of the tested columns. The elevated temperature tests reported by Pauli et al. [7] were performed on SHS and rectangular hollow sections (RHS), and included both stub columns and long columns. The stub columns were fixed against displacement and rotation at both ends, apart from axial displacement at the loaded end, while the long columns were pinned at both ends and allowed in-plane rotation of the member about the minor axis. All columns were made of S355 hot-finished sheets which were rolled into shape at ambient temperature and welded closed. The elevated temperature tests were performed under isothermal loading conditions whereby the columns were first heated to a target temperature of 400,550 and $700^{\circ} \mathrm{C}$ and when thermal equilibrium was reached at the desired temperature, a mechanical load was applied at a strain rate of $0.1 \% / \mathrm{min}$ until failure. The same modelling procedures were employed for both the room temperature and elevated temperature tests by incorporating the material properties corresponding to the test temperature under consideration. A summary of these tests is provided in Table 1 and Table 2.

Table 1. Summary of the test conditions reported by Wang and Gardner [10] at ambient temperature

\begin{tabular}{|c|c|c|c|c|c|c|c|}
\hline Specimen & $\begin{array}{l}\text { Steel } \\
\text { grade }\end{array}$ & $\begin{array}{c}\text { Nominal section size } \\
(\mathrm{mm})\end{array}$ & $\begin{array}{c}\mathrm{L} \\
(\mathrm{mm})\end{array}$ & $\begin{array}{c}\theta \\
\left({ }^{\circ} \mathrm{C}\right) \\
\end{array}$ & $\begin{array}{c}\text { End- } \\
\text { condition }\end{array}$ & $\begin{array}{l}\text { Buckling } \\
\text { axis }\end{array}$ & $\begin{array}{l}\mathrm{N}_{\mathrm{u}, \text { test }} \\
(\mathrm{kN})\end{array}$ \\
\hline C3L1 & S460N & $100 \times 100 \times 5$ & 858 & Ambient & Pinned & Major & 878 \\
\hline C3L2 & S460N & $100 \times 100 \times 5$ & 1759 & Ambient & Pinned & Major & 798 \\
\hline C3L3 & S460N & $100 \times 100 \times 5$ & 2949 & Ambient & Pinned & Major & 557 \\
\hline C4L1 & S690Q & $50 \times 50 \times 5$ & 426 & Ambient & Pinned & Major & 690 \\
\hline C4L2 & S690Q & $50 \times 50 \times 5$ & 669 & Ambient & Pinned & Major & 637 \\
\hline C4L3 & S690Q & $50 \times 50 \times 5$ & 906 & Ambient & Pinned & Major & 562 \\
\hline C4L4 & S690Q & $50 \times 50 \times 5$ & 1222 & Ambient & Pinned & Major & 391 \\
\hline C4L5 & S690Q & $50 \times 50 \times 5$ & 1529 & Ambient & Pinned & Major & 248 \\
\hline C4L6 & S690Q & $50 \times 50 \times 5$ & 1700 & Ambient & Pinned & Major & 201 \\
\hline C4L7 & S690Q & $50 \times 50 \times 5$ & 1860 & Ambient & Pinned & Major & 166 \\
\hline C4L8 & S690Q & $50 \times 50 \times 5$ & 2150 & Ambient & Pinned & Major & 119 \\
\hline C5L1 & S690Q & $100 \times 100 \times 5.6$ & 858 & Ambient & Pinned & Major & 1571 \\
\hline C5L2 & S690Q & $100 \times 100 \times 5.6$ & 1760 & Ambient & Pinned & Major & 1420 \\
\hline C5L3 & S690Q & $100 \times 100 \times 5.6$ & 2950 & Ambient & Pinned & Major & 680 \\
\hline
\end{tabular}

\subsection{Material parameters}

Tensile coupon tests on material extracted from the flat faces of the S460N and S690Q HSS columns were performed to measure their engineering stress-strain response and were reported by Wang et al. [11]; these were used in the FE models of the ambient temperature tests. Similarly, for the elevated temperature FE models, tensile coupons were extracted from flat faces of S355 columns. Tensile tests were conducted at ambient, 400,550 and $700^{\circ} \mathrm{C}$ under isothermal conditions and the measured engineering stress-strain response and were reported by Knobloch et al. [12]. 
Table 2. Summary of the test conditions reported by Pauli et al. [7] at elevated temperature

\begin{tabular}{cccccccc}
\hline Specimen & $\begin{array}{c}\text { Steel } \\
\text { grade }\end{array}$ & $\begin{array}{c}\text { Nominal section size } \\
(\mathrm{mm})\end{array}$ & $\begin{array}{c}\mathrm{L} \\
(\mathrm{mm})\end{array}$ & $\begin{array}{c}\theta \\
\left({ }^{\circ} \mathrm{C}\right)\end{array}$ & $\begin{array}{c}\text { End- } \\
\text { condition }\end{array}$ & $\begin{array}{c}\text { Buckling } \\
\text { axis }\end{array}$ & $\begin{array}{c}\mathrm{N}_{\mathrm{u}, \text { test }} \\
(\mathrm{kN})\end{array}$ \\
\hline S3 & S355 & $160 \times 160 \times 5$ & 480 & 400 & Fixed & Minor & 795 \\
S6 & S355 & $160 \times 160 \times 5$ & 480 & 550 & Fixed & Minor & 468 \\
S5 & S355 & $160 \times 160 \times 5$ & 480 & 700 & Fixed & Minor & 138 \\
S02 & S355 & $60 \times 120 \times 3.6$ & 360 & 400 & Fixed & Minor & 408 \\
S03 & S355 & $60 \times 120 \times 3.6$ & 360 & 550 & Fixed & Minor & 257 \\
S06 & S355 & $60 \times 120 \times 3.6$ & 360 & 700 & Fixed & Minor & 74 \\
L2 & S355 & $160 \times 160 \times 5$ & 1840 & 400 & Pinned & Minor & 760 \\
L5 & S355 & $160 \times 160 \times 5$ & 1840 & 550 & Pinned & Minor & 467 \\
L6 & S355 & $160 \times 160 \times 5$ & 1840 & 700 & Pinned & Minor & 130 \\
L08 & S355 & $60 \times 120 \times 3.6$ & 1840 & 400 & Pinned & Minor & 242 \\
L10 & S355 & $60 \times 120 \times 3.6$ & 1840 & 550 & Pinned & Minor & 186 \\
L05 & S355 & $60 \times 120 \times 3.6$ & 1840 & 700 & Pinned & Minor & 71 \\
\hline
\end{tabular}

ABAQUS requires the material stress-strain curves to be specified in terms of true stress $\sigma$ true and true plastic strain $\varepsilon_{\mathrm{pl}}$, which were derived from the nominal engineering stress-strain curves using Eqs. (1) and (2) respectively, where $\sigma_{\text {nom }}$ and $\varepsilon_{\text {nom }}$ are the engineering stress and strain, respectively, and Ea is the elastic modulus. Poisson's ratio was taken a s 0.3 at ambient and elevated temperatures in accordance with EN 1993-1-1 [13].

$$
\begin{aligned}
& \sigma_{\text {true }}=\sigma_{\text {nom }}\left(1+\varepsilon_{\text {nom }}\right) \\
& \varepsilon_{\mathrm{pl}}=\ln \left(1+\varepsilon_{\text {nom }}\right)-\frac{\sigma_{\text {true }}}{E_{\mathrm{a}}}
\end{aligned}
$$

\subsection{Boundary conditions and load application}

Owing to symmetry in the geometry and boundary conditions of the tested columns only half of the cross-section and half of the column length was modelled. The test boundary conditions were replicated by restraining suitable displacement and rotation degrees of freedom at the column ends. All boundary conditions were applied through reference points at the column ends. For the elevated temperature stub column tests with fixed ends, all the six degrees of freedom of the lower reference point were restrained, while the upper reference point was allowed to move along the column axis and was fixed against all the other five degrees of freedom. To model the pinned end support condition of the ambient temperature tests, all degrees of freedom of the lower reference point, except rotation about one axis, were fixed, while the upper reference point was free to displace along the column axis and rotate about the same axis as the lower reference point. The elevated temperature pin-ended columns were modelled in the same way with the exception that the rotation axis was set as the minor axis in all cases. The measured geometric dimensions were used in each model to replicate the corresponding test behaviour. All columns were concentrically loaded through their upper reference point. The modified Riks method, which is a variation of the classical arc length method, was used to trace the load-deformation response of each of the modelled columns and to determine ultimate test load.

\subsection{Geometric imperfection, mesh type and residual stresses}

All structural members contain geometric imperfections which are introduced during production, fabrication and handling. Initial imperfections in the form of the lowest local and global buckling mode, obtained from a linear elastic eigenvalue buckling analysis, with the amplitudes as those measured in the tests [10], [11] were assigned to the numerical models. Residual stresses, which also tend to develop during manufacturing (e.g. during the cold-forming process) or welding, were not explicitly incorporated into the models due to their low measured amplitudes and minimal influence on the member compressive resistance in similar fabricated columns reported in [11]. Shell elements were adopted to simulate the high strength steel tubular hollow section columns, as have been adopted in similar studies (e.g. [8], [10]). The four-node shell elements with double curvature and reduced 
integration (S4R) have been used in all the FE models. Based on a mesh sensitivity assessment, the model employed a mesh comprising cubic elements whereby the size of the elements was defined by the thickness of the section in that area.

\subsection{Validation of the model}

The developed numerical models described above were able to capture accurately the observed loaddeformation history of the high strength steel columns. Fig. 1 shows the load-lateral deflection curves derived from the numerical models of the C4L6 and C5L3 members which are compared with their respective test responses. A summary of the ultimate test load $\mathrm{N}_{\mathrm{u} \text {,test }}$ and ultimate FE load $\mathrm{N}_{\mathrm{u} \text {,model }}$ for the ambient temperature tests are presented in Table 3. The FE model gives a mean $\mathrm{N}_{\mathrm{u} \text {,test }} / \mathrm{N}_{\mathrm{u} \text {,model }}$ value of 1.01 and a COV of $5.0 \%$. For the elevated temperature tests, the results obtained from the validation study are presented in Table 4 where $\mathrm{N}_{\mathrm{u} \text {,test }} / \mathrm{N}_{\mathrm{u} \text {,model }}$ is a measure of how accurately the FE model predicts the ultimate load. For the stub columns, the FE model gives a mean $\mathrm{N}_{\mathrm{u} \text {,test }} / \mathrm{N}_{\mathrm{u} \text {,model }}$ value of 1.09 and a coefficient of variation of $7.9 \%$. On the other hand, for the slender columns the

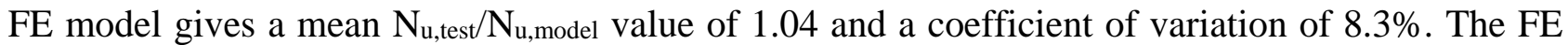
model generally underestimates the ultimate load of both the stub and slender columns at elevated temperatures and thus provides a safe side prediction for the fire resistance of steel columns. From the results provided in Table 3 and Table 4, it is concluded that the FE model is adequate for predicting the ultimate strengths of HSS columns at ambient temperature and normal strength steel at elevated temperature.

(a)

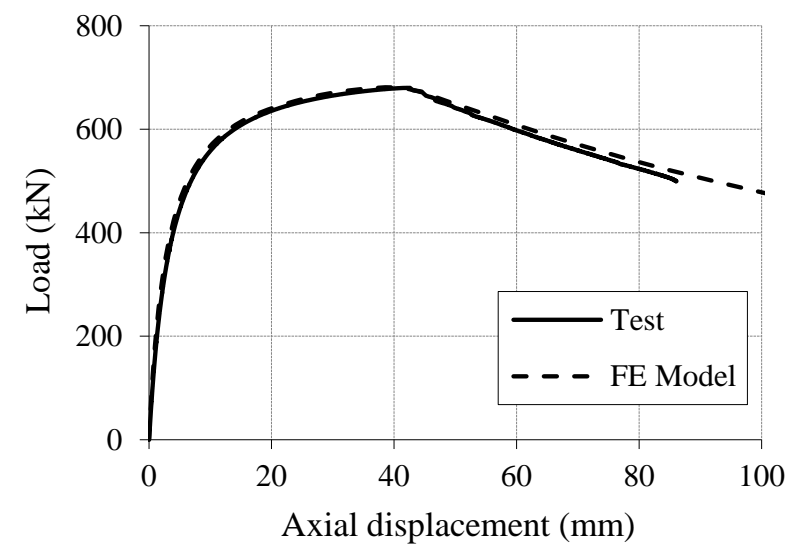

(b)



Fig. 1. Comparison of the load -axial displacement curves for column (a) C4L6 and (b) C5L3

\section{PARAMETRIC STUDIES}

Following the validation of the FE models, a series of parametric studies was performed to generate further structural performance data to assess the suitability of the Eurocode [2] buckling curves for HSS compression members at elevated temperature. To investigate the effect of material grade, the parametric studies were performed for two HSS grades S690QL and S700MC (referred to as Steel A and Steel B herein). Since the focus was on the flexural buckling response of HSS compression members, a limited number of fixed cross-section geometries with varying member lengths were modelled for each of the HSS grades. For modelling convenience, the parametric study models were performed isothermally at the following temperatures: $20,400,500,600,700$ and $800^{\circ} \mathrm{C}$. This involved using the material properties for a given temperature $\theta$ and increasing the applied load until failure. Since the influence of time dependent effects, e.g. creep, was not included in the developed FE models, this approach was considered acceptable.

The outer dimensions of the parametric study models were fixed to SHS $100 \times 100$ and RHS $100 \times$ 50 , for both grades. Two different thicknesses were then selected for each of the considered crosssections such that one Class 1 and one Class 3 cross-section, as specified in Eurocode 3 Part 1-1 
[13], were modelled in each case, resulting in a total of four cross-sections. For the case of the RHS models, buckling about both major and minor axes was considered to investigate if different buckling curves are required for each case. All columns were modelled as pin ended providing a slenderness $(\bar{\lambda})$ range of 0.5 to 2.5 . The measured elevated temperature stress-strain curves for steel A (S690QL) and B (S700MC) determined from a previous study [9], were modified into the true stress versus plastic strain values and incorporated into the models. The same modelling assumptions as explained in the previous sections were employed. The global imperfection amplitude was taken as L/1000, where $\mathrm{L}$ is the column length, in accordance with the permitted out-of-straightness tolerance in EN 1090-2 [14]. The local imperfection amplitude ( $\left.\omega_{0}\right)$ shown in Eq. (3) was taken as that predicted by the Dawson and Walker model and used for a similar study on HSS members [15].

$$
\omega_{0}=0.028 t\left(f_{y} / f_{c r}\right)^{0.5}
$$

where $\mathrm{t} \quad$ is the thickness,

$\mathrm{f}_{\mathrm{y}} \quad$ is the material yield strength,

$\mathrm{f}_{\mathrm{cr}} \quad$ is the elastic critical buckling stress of the most slender constituent plate element in the section

Similar to the validation models, because of symmetry in the geometry and boundary conditions only half of the section, and half of the member length, was modelled. The results are presented in the following section.

Table 3. Comparison of test and FE results for Wang and Gardner [10] tests

\begin{tabular}{lcccc}
\hline Name & $\begin{array}{c}\text { Steel } \\
\text { grade }\end{array}$ & $\begin{array}{c}\mathrm{N}_{\mathrm{u}, \text { test }} \\
(\mathrm{kN})\end{array}$ & $\begin{array}{c}\mathrm{N}_{\mathrm{u} \text {,model }} \\
(\mathrm{kN})\end{array}$ & $\mathrm{N}_{\mathrm{u}, \text { test }} / \mathrm{N}_{\mathrm{u}, \text { model }}$ \\
\hline C3L1 & S460N & 878 & 888 & 0.99 \\
C3L2 & S460N & 798 & 850 & 0.94 \\
C3L3 & S460N & 557 & 576 & 0.97 \\
C4L1 & S690Q & 690 & 705 & 0.98 \\
C4L2 & S690Q & 637 & 588 & 1.08 \\
C4L3 & S690Q & 562 & 520 & 1.08 \\
C4L4 & S690Q & 391 & 360 & 1.09 \\
C4L5 & S690Q & 248 & 230 & 1.08 \\
C4L6 & S690Q & 201 & 195 & 1.03 \\
C4L7 & S690Q & 166 & 165 & 1.01 \\
C4L8 & S690Q & 119 & 126 & 0.94 \\
C5L1 & S690Q & 1571 & 1608 & 0.98 \\
C5L2 & S690Q & 1420 & 1376 & 1.03 \\
C5L3 & S690Q & 680 & 679 & 1.00 \\
\hline
\end{tabular}

Table 4. Comparison of test and FE results for Pauli et al.[7] tests

\begin{tabular}{|c|c|c|c|c|}
\hline \multirow[b]{2}{*}{ Name } & \multicolumn{2}{|c|}{ Test } & \multirow[b]{2}{*}{$\begin{array}{c}\mathrm{N}_{\mathrm{u} \text {,model }} \\
(\mathrm{kN})\end{array}$} & \multirow[b]{2}{*}{$\begin{array}{l}\mathrm{N}_{\mathrm{u}, \text { test }} / \\
\mathrm{N}_{\mathrm{u}, \text { model }}\end{array}$} \\
\hline & $\begin{array}{c}\text { Temperature } \\
\left({ }^{\circ} \mathrm{C}\right)\end{array}$ & $\begin{array}{l}\mathrm{N}_{\mathrm{u}, \text { test }} \\
(\mathrm{kN})\end{array}$ & & \\
\hline S3 & 400 & 795 & 767 & 1.04 \\
\hline S6 & 550 & 468 & 474 & 0.99 \\
\hline S5 & 700 & 138 & 128 & 1.08 \\
\hline S02 & 400 & 408 & 330 & 1.24 \\
\hline S03 & 550 & 257 & 218 & 1.18 \\
\hline S06 & 700 & 74 & 71 & 1.04 \\
\hline L2 & 400 & 760 & 701 & 1.08 \\
\hline L5 & 550 & 467 & 443 & 1.05 \\
\hline L6 & 700 & 130 & 119 & 1.10 \\
\hline L08 & 400 & 242 & 262 & 0.92 \\
\hline L10 & 550 & 186 & 165 & 1.13 \\
\hline L05 & 700 & 71 & 64 & 1.10 \\
\hline
\end{tabular}




\section{ANALYSIS OF RESULTS AND RECOMMENDATION}

This section presents and compares the results from the parametric study with existing structural fire design guidelines provided in Eurocode 3 Part 1-2 [2]. In accordance with Eurocode 3 Part 1-2 [2],

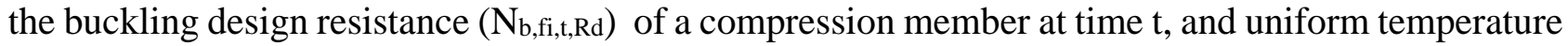
$\theta$, can be determined from Eq. (4) and Eq. (5).

$$
\begin{array}{ll}
\mathrm{N}_{\mathrm{b}, \mathrm{fi}, \mathrm{t}, \mathrm{Rd}}=\frac{\chi_{\mathrm{fi}} \mathrm{Ak}_{\mathrm{y}, \theta} \mathrm{f}_{\mathrm{y}, 20}}{\gamma_{\mathrm{M}, \mathrm{fi}}} & \text { for Class 1-3 members } \\
\mathrm{N}_{\mathrm{b}, \mathrm{fi}, \mathrm{t}, \mathrm{Rd}}=\frac{\chi_{\mathrm{fi}} \mathrm{A}_{\mathrm{eff}} \mathrm{k}_{0.2 \mathrm{p}, \theta} \mathrm{f}_{0.2 \mathrm{p}, 20}}{\gamma_{\mathrm{M}, \mathrm{fi}}} & \text { for Class 4 member }
\end{array}
$$

where $\chi_{\mathrm{fi}} \quad$ is the reduction factor for flexural buckling in the fire design situation,

A is the gross area cross-section of the structural member,

$f_{y, 20}$ is the effective yield strength, taken as the stress at $2 \%$ total strain at ambient temperature

$\mathrm{ky}_{\mathrm{y}, \theta} \quad$ is the reduction factor for the effective yield strength (i.e. $\mathrm{ky}_{\mathrm{y}, \theta}=\mathrm{fy}_{\mathrm{y}, \theta} / \mathrm{f}_{\mathrm{y}, 20}$ ) taken from [9]

$\gamma_{\mathrm{M}, \mathrm{fi}}$ is the partial factor for fire situation which is taken as 1.0 in this study,

$A_{\text {eff }} \quad$ is the effective cross section area determined in accordance with [16]

$\mathrm{f}_{0.2 \mathrm{p}, 20}$ is the $0.2 \%$ proof stress at ambient temperature

$\mathrm{k}_{0.2 \mathrm{p}, \theta}$ is the reduction factor for the $0.2 \%$ proof strength (i.e. $\mathrm{k}_{0.2 \mathrm{p}, \theta}=\mathrm{f}_{0.2 \mathrm{p}, \theta} / \mathrm{f}_{0.2 \mathrm{p}, 20}$ ) taken from [9].

In classifying cross-sections at elevated temperature $\theta$, a reduced strength parameter $\left(\varepsilon=0.85\left(235 / \mathrm{f}_{\mathrm{y}}\right)\right.$ ${ }^{0.5}$ ) is used to account for the decline in strength and stiffness at elevated temperatures. This means that in this parametric study, the Class 3 members at ambient temperature change to Class 4 at temperature $\theta$, whilst Class 1 classification remains unchanged.

The results from the parametric study, normalised against the appropriate squash load $\left(\mathrm{Af}_{\mathrm{y}, 20 \mathrm{ky}, \theta \text { and }}\right.$

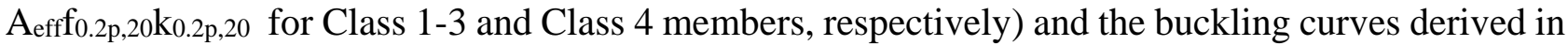
accordance with Eurocode 3 Part 1-2 [2] are presented in Fig. 2 and Fig. 3. The Eurocode buckling curve for fire design is of the same general form as the ambient temperature buckling curve with the exception of the following: no yield plateau (i.e. $\bar{\lambda}=0$ ), the use of the yield dependent imperfection factor $\left(\alpha=0.65\left(235 / \mathrm{f}_{\mathrm{y}}\right)^{0.5}\right)$, and the non-dimensional slenderness at temperature $\theta, \bar{\lambda}_{\theta}$ defined in Eq.(6) and Eq. (7).

$$
\begin{array}{ll}
\bar{\lambda}_{\theta}=\bar{\lambda}\left(\mathrm{k}_{\mathrm{y}, \theta} / \mathrm{kEa}, \theta_{\theta}\right)^{0.5} & \text { for Class } 1-3 \text { members } \\
\bar{\lambda}_{\theta}=\bar{\lambda}\left(\mathrm{k}_{0.2 \mathrm{p}, \theta} / \mathrm{k}_{\mathrm{Ea}, \theta}\right)^{0.5} & \text { for Class } 4 \text { member }
\end{array}
$$

where $\bar{\lambda} \quad$ is the non-dimensional slenderness at ambient,

$\mathrm{kEa}_{\mathrm{Ea} \theta} \quad$ is the reduction factor the elastic modulus (i.e. $\mathrm{kEa}, \theta=\mathrm{E}_{\mathrm{a}, \theta} / \mathrm{E}_{\mathrm{a}, 20}$ )

Fig. 2 and Fig. 3 present the buckling curves and FE results for Class 1 and Class 3 SHS and RHS members, respectively made from steel A (S690QL) and B (S700MC). With reference to Fig. 2(a), the Eurocode buckling curve is generally conservative with respect to the buckling coefficients for steel A (S690QL), with the exception of $800^{\circ} \mathrm{C}$ at non-dimensional slenderness $\bar{\lambda}_{\theta}$ values below 1 . Similarly, in Fig 2(b) the Eurocode buckling curve is conservative and adequately predicts the ultimate buckling load for steel B (S700MC) at all temperatures which is linked to the better strength and stiffness properties observed in previous study [9]. In Fig. 3, it can be seen that generally, the Eurocode curve is conservative with respect to the buckling coefficients and safely predicts the 
buckling behaviour of class 3 sections at elevated temperatures. There is little disparity between the major and minor buckling axes for RHS sections.

At non-dimensional slenderness $\bar{\lambda}_{\theta}$ values below 1.5, steel A (S690QL) had higher buckling coefficients and more scatter between the buckling coefficients compared to steel B (S700MC). This could be due to the shape of stress-strain curve of the two materials which are presented in Fig. 4. Whilst for steel B (S700MC), the shape of the stress-strain curve is non-linear at all temperatures and quite consistent in shape, that is not the case for steel A (S690QL). As shown in Figure 4(a), steel A (S690QL) displays a bi-linear elastic-plastic response up to the $2 \%$ total strain at $20^{\circ} \mathrm{C}$, and shows more non-linear behaviour at higher temperatures. The varying degree of nonlinearity of the steel A (S690QL) with temperature leads to different buckling responses and hence results in the increased scatter in the obtained results. Members with a non-dimensional slenderness greater than 1.5 buckle elastically, where the average stress falls in the elastic part of the stress-strain curve, and as expected there is little difference in the elevated temperature buckling strength of columns of steel A (S690QL) and B (S700MC).

(a)

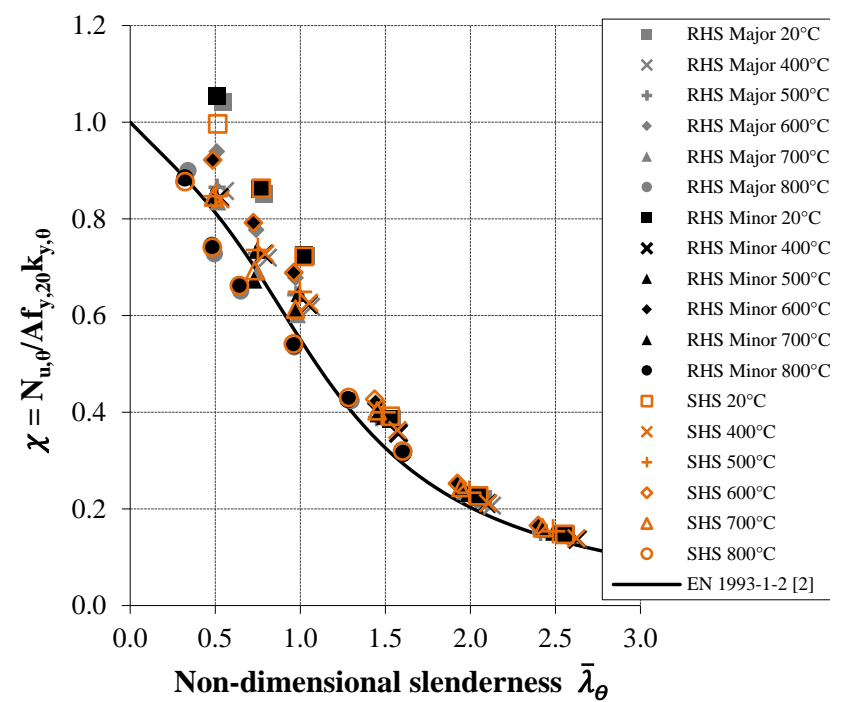

(b)

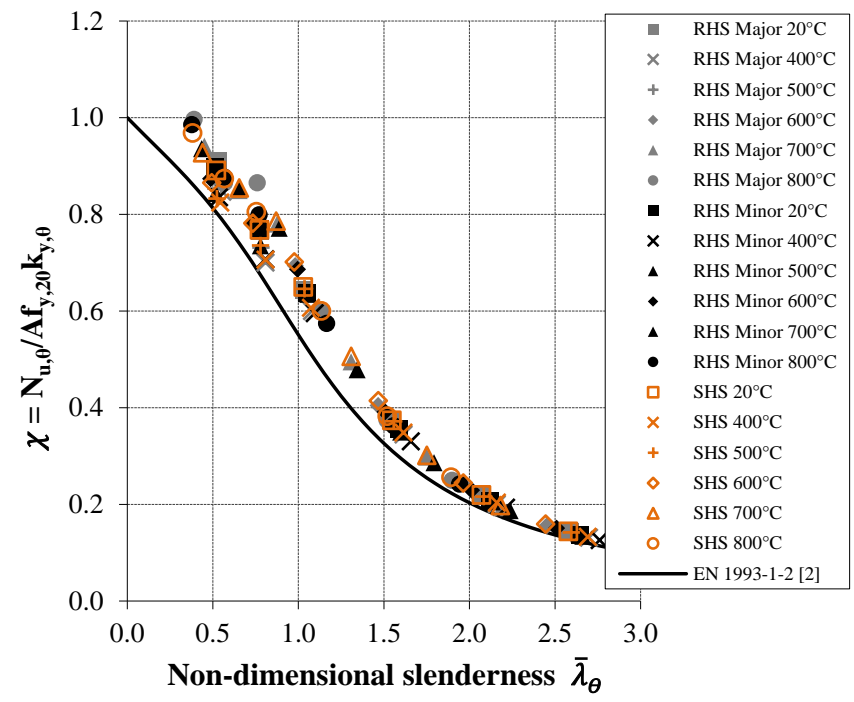

Fig. 2. Comparison of EN 1993-1-2 buckling curve and FE results for Class 1 SHS and RHS (a) A (S690QL) and (b) steel B (S700MC)

(a)

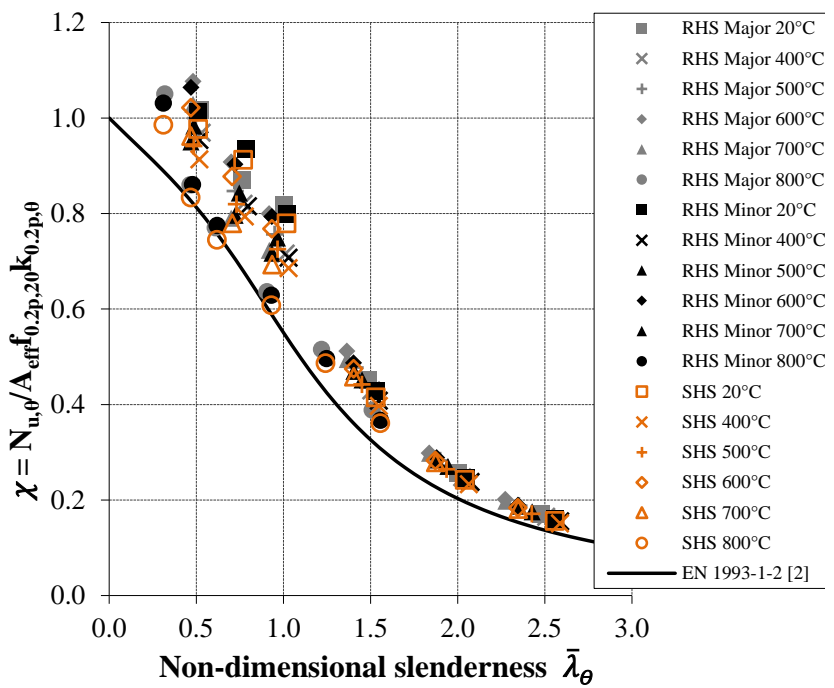

(b)



Fig. 3. Comparison of EN 1993-1-2 buckling curve and FE results for Class 3 SHS and RHS (a) steel A (S690QL) and (b) steel B (S700MC) 

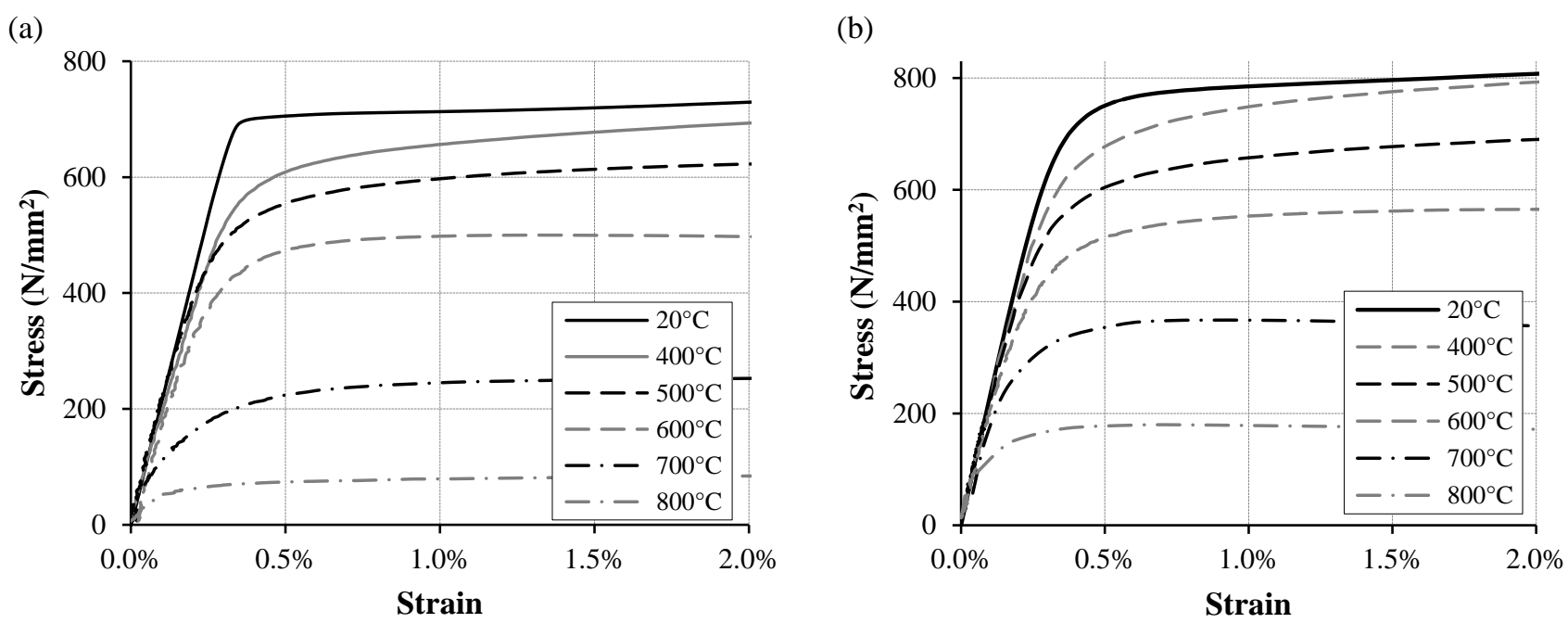

Fig. 4. Engineering stress-strain curves at up to 2.0\% strain for (a) steel A (S690QL) and (b) steel B (S700MC)

It should be noted that the use of the stress at $2 \%$ total strain $f_{y, \theta}$ in the analysis reflects the allowance for high strains to develop in the member during a fire. This is generally tolerable for steel members as it is assumed that damaged elements will either be repaired or replaced after the fire [17]. However, since the buckling behaviour of columns is controlled by material stiffness, which reduces significantly beyond the $0.2 \%$ proof stress, it is believed that the $0.2 \%$ proof stress is a more appropriate parameter for predicting the buckling resistance of columns of all cross-section classes. Fig. 5 presents the ultimate loads from the parametric studies normalised by Af $0.2 p, 20 \mathrm{k} 0.2 \mathrm{p}, \theta$, with the Eurocode curve also depicted. Comparing Fig. 5(a) and (b) to Fig. 2(a) and (b), shows that


temperature approximately converge into one curve, which is more prominent for steel A (S690QL), and avoids the need for temperature dependent buckling curves. Also, while the current EN 1993-12 buckling curve has been shown to be suitable for steel B (S700MC), a slightly lower curve may be needed for steel A (S690QL).

(a)



(b)



Fig. 5. Comparison of EN 1993-1-2 buckling curve and FE results for Class 1 SHS and RHS normalised by $\mathrm{Af}_{0.2 \mathrm{p}, 20 \mathrm{k}_{0.2 \mathrm{p}, \theta}}$ for (a) steel A (S690QL) and (b) steel B (S700MC) 


\section{CONCLUSIONS}

In this paper, a numerical study investigating the flexural behaviour of HSS columns, including a detailed description of the FE model and validation results, was presented. Once validated, the model was used to perform parametric studies on the behaviour of S690QL and S700MC steel columns at elevated temperature. The results from the parametric studies were analysed and it was shown that the Eurocode generally provides conservative results with respect to the buckling coefficients and safely predicts the buckling resistance of S700MC, while a lower buckling curve may be needed for S690QL. It was also shown that the $0.2 \%$ proof stress rather than the stress at $2 \%$ total strain is a better parameter for deriving buckling curves in fire.

\section{ACKNOWLEDGMENT}

The authors would like to acknowledge the EPSRC and TWI Ltd. for the financial support provided for this work through an Industrial CASE award scheme.

\section{REFERENCES}

[1] ABAQUS, Version 6.12-2. Dassault Systèmes Simulia Corp. USA, 2015

[2] EN 1993-1-2. Eurocode 3: Design of steel structures - Part 1-2: General rules - Structural fire design. CEN, Brussels, 2005

[3] EN 1993-1-12. Eurocode 3: Design of steel structures - Part 1-12: Additional rules for the extension of EN 1993 up to steel grades S 700. CEN, Brussels, 2007

[4] BS 9999. Fire safety in the design, management and use of buildings - Code of practice. BSI, London, UK, 2017

[5] Franssen, J.-M., Talamona, D., Kruppa, J., Cajot, L.G. "Stability of steel columns in case of fire: experimental evaluation”. Journal of Structural Engineering 124, No. 2, pp. 158-163, 1998

[6] Talamona, D., Franssen, J.M., Schleich, J.B., Kruppa, J. "Stability of steel columns in case of fire: Numerical Modelling”. Journal of Structural Engineering 123, No. 6, pp. 713-720, 1997

[7] Pauli, J., Somaini, D., Knobloch, M., Fontana, M. "Experiments on steel under fire conditions”. ETH Zurich, Institute of Structural Engineering. IBK test report No. 340, Zurich, Switzerland, 2012

[8] Chen, J., Young, B. "Design of high strength steel columns at elevated temperatures". Journal of Constructional Steel Research 64, No. 6, pp. 689-703, 2008

[9] Winful, D.A., Cashell, K.A., Barnes, A.M., Pargeter, R.J "Elevated temperature material properties of high strength steel”, ICE Building and structures (submitted), 2017

[10] Wang, J., Gardner, L. "Flexural buckling of hot-finished high strength steel SHS and RHS columns". ASCE (submitted), 2017

[11] Wang, J., Afshan, S., Schillo, N., Theofanous, M., Feldmann, M., Gardner, L. "Material properties and compressive local buckling response of high strength square and rectangular hollow sections". Engineering Structures 130, pp. 297-315, 2017

[12] Knobloch, M., Pauli, J., Fontana, M. "Influence of the strain-rate on the mechanical properties of mild carbon steel at elevated temperatures”. Materials and Design 49, pp. 553-565, 2013

[13] EN 1993-1-1. Eurocode 3: Design of steel structures - Part 1-1: General rules and rules for buildings. CEN, Brussels, 2005

[14] BS EN 1090-2. Execution of steel structures and aluminium structures - Part 2: Technical requirements for steel structures. BSI, London, UK, 2008

[15] Wang, J., Afshan, S., Gkantou, M., Theofanous, M., Baniotopoulos, C., Gardner, L. "Flexural behaviour of hot-finished high strength steel square and rectangular hollow sections". Journal of Constructional Steel Research 121, pp. 97-109, 2016

[16] EN 1993-1-5. Eurocode 3: Design of steel structures - Part 1-5: Plated structural elements. CEN, Brussels, 2006

[17] Gardner, L., Bu, Y., Francis, P., Baddoo, N.R., Cashell, K.A., McCann, F. “Elevated temperature material properties of stainless steel alloys”. Construction and Building Material 114, pp. 977-997, 2016 